This item was submitted to Loughborough's Research Repository by the author.

Items in Figshare are protected by copyright, with all rights reserved, unless otherwise indicated.

\title{
Public service performance: Exploring the effects of strategy configurations among ownership types
}

\section{PLEASE CITE THE PUBLISHED VERSION}

https://doi.org/10.1080/10967494.2018.1461151

\section{PUBLISHER}

(c) Taylor \& Francis (Routledge)

\section{VERSION}

AM (Accepted Manuscript)

\section{PUBLISHER STATEMENT}

This is an Accepted Manuscript of an article published by Taylor \& Francis in International Public Management Journal on 14 May 2018, available online: http://www.tandfonline.com/10.1080/10967494.2018.1461151.

\section{LICENCE}

CC BY-NC-ND 4.0

\section{REPOSITORY RECORD}

Hodgkinson, lan, and Paul Hughes. 2018. "Public Service Performance: Exploring the Effects of Strategy Configurations Among Ownership Types". figshare. https://hdl.handle.net/2134/32552. 


\title{
Public Service Performance: Exploring the Effects of Strategy Configurations among Ownership Types
}

\section{Running Head: 'Strategy, Ownership and Performance'}

\begin{abstract}
We focus on strategic management as a critical issue for service delivery and explore the effects of strategy configurations among ownership types. Examining the strategic stance of public, nonprofit, and private service providers, we explore how and where different ownership types generate performance returns across customer, business, and social dimensions. Using a configurational approach, we find ideal strategy profiles among ownership types. The ideal strategy profile delivers both social and business performance returns for public; customer and social performance advantages for nonprofit; but only customer performance gains for private ownership types. Through additional analysis differences in the identity of prioritized stakeholders between ownership types are explored to interpret differences in strategy and performance. The influence of local government for public ownership versus the prioritization of funders for nonprofit and private ownership types is the one clear difference between service providers. Implications for public management theory and practice are identified and discussed.
\end{abstract}

Keywords: ownership, strategy, configuration analysis, ideal profile, customer performance, business performance, social performance, stakeholders. 


\section{INTRODUCTION}

“Organizations may possess multiple strategies, with varying degrees of priority accorded to different basic strategic stances (ideal types). Such hybrid organizational strategies are nonetheless likely to be associated with certain structures, processes and environments, which reflect the core argument of configurational theories that organizational viability is dependent on the fit between internal and external characteristics” (Beynon, Andrews, and Boyne 2015, 2)

Strategy is a means by which organizations can improve their performance and provide better public services (Boyne and Walker 2010) and is often conceptualized as the strategic stance of organizations. Strategy here is not categorical but can be understood as a set of different basic stances that combine in different ways to create a range of strategy configurations that service providers pursue (Beynon et al. 2015). This view reflects extant public management research that has established strategic stance as a multidimensional phenomenon (e.g. Andrews, Boyne, and Walker 2006; Andrews, Boyne, Law, and Walker 2008, 2009; Hodgkinson and Hughes 2014; Meier, O'Toole, Boyne, and Walker 2007; Meier, O’Toole, Boyne, Walker, Andrews 2010; Walker et al. 2010).

Consistent with configurational theory, the form strategy takes and its influence on service performance might depend on the ownership type responsible for service delivery, however, this has received little scholarly attention (Andrews, Boyne and 
Walker 2011a). Subsequently, there is limited knowledge on the role of strategy at the disaggregated service level reducing knowledge on the performance effects of strategy in the sector, as highlighted by Boyne and Walker $(2004,2010)$ and Walker, Andrews, Boyne, Meier, and O’Toole (2010). This gives rise to our exploratory research question: how and where do different ownership types generate performance impacts? Informed by configurational theory, we examine the ideal strategy profile among different ownership types in public leisure delivery: public, nonprofit, and private service providers. In doing so, we seek to explain the performance effects of strategy configurations among these ownership types. Alongside this, additional analysis is conducted to explore differences in the prioritized stakeholders that potentially inform strategic formation and performance goals among ownership types.

This exploratory study contributes to public management theory in three important ways. First, we examine strategy effects across a variety of performance dimensions, since a gain on one dimension may be obtained by sacrificing another (Andrews et al. 2011a); in doing so we extend research on the relationship between strategy and different dimensions of performance (Boyne and Walker 2010), accounting for performance trade-offs that are often neglected (Mikkelsen 2017). Second, and to the best of our knowledge, this is the first study to test empirically the strategy configurations of the highest performing service providers among ownership types. Thus, linked to the first contribution we determine the ideal strategy configurations across different performance outcomes for each ownership type. Here we are responding to the call made by Boyne and Walker (2010) for a more nuanced examination of strategy and 
performance. Third, it remains unclear if public service providers can be understood as operating in the same strategic space as external nonprofit and private service providers, despite operating in the same functional space. Thus, through additional analysis we explore the identity of prioritized stakeholders among ownership types, a considered best practice in performance comparison studies (Andersen, Boesen, and Pedersen 2016). Collectively, we contribute to public service practice by helping policymakers to arrive at better judgments on the circumstances under which ownership type matters, a contribution called for by Andrews et al. (2011a).

The article is structured as follows: we first outline the theoretical foundations and exploratory model that frame the data analysis. Next, we identify ideal strategy profiles among ownership types and report their effects across customer, business, and social performance dimensions. Additional analysis is used to capture the identity of prioritized stakeholder groups to help interpret the strategy configurations and their performance effects among ownership types. Results and implications are then discussed.

\section{THEORETICAL FRAMEWORK}

\section{Strategic stance}

The focus of this exploratory study is the role of strategic stance on the ownership-performance relationship, which captures the intended approach of the organization rather than its realized strategy (Andrews et al. 2006). In response to Boyne's (2002) observation that there is no knowledge on whether successful management strategies in the private sector can be easily drawn upon by public agencies, 
recent research has established the value of Miles and Snow's prospector-defenderreactor typology to public service organizations (e.g. Andrews et al. 2006, 2008, 2009). Such a strategy typology seeks to classify a public service organization’s strategy into one of a mutually exclusive set of basic strategy types (or boxes). These are presented as competitive strategies that serve as the foundation for competitive advantage. Such typologies are pertinent to New Public Management (NPM) oriented settings that are characterized by: a high degree of (i) administrative autonomy, (ii) performance-based budgets and (iii) market-like conditions; making these settings particularly receptive to conventional models of strategic management (Hansen and Ferlie 2016). Examples of such public service settings include public transit, leisure and culture services, education, some forms of healthcare, and so on. As explained aptly by Hansen and Ferlie (2016; 8): "Autonomy levels should be high because one fundamental contention is that the organizations can choose (Porter 1996) their strategy or even their industry. Market-like conditions should be high because the goal is to achieve a competitive advantage (Porter 1980)...Finally, the goal of strategic positioning is to perform better than competitors (to earn more profit) and this assumes that the budgetary funding should be performance-based"

Porter's $(1980,1985)$ typology of strategic positioning is an alternative to Miles and Snow's and is equally applicable to NPM oriented service settings (Hansen and Ferlie 2016). Porter (1985) offers three generic strategies for achieving superior performance: cost leadership, differentiation, and focus. Cost leadership is to be the lowest cost provider relative to direct competitors, where emphasis is focused on minimizing all costs 
in all areas at the expense of value adding activities (Porter 1985). Typically, a successful cost leader can provide services of comparable quality to other equivalent offerings in the market place, while maintaining the lowest cost base relative to competitors (Hodgkinson 2013). Differentiation by adding greater value relative to competitors can be used to create a unique customer experience to the masses (Porter 1985). This strategy does not ignore the importance of costs, but they are of secondary significance to the service offering (Hodgkinson 2013). Unlike cost leadership, however, there can be more than one successful differentiator if there are a number of attributes that are widely valued by customers (Porter 1985). The final generic strategy of focus is built around serving a particular niche very well and more effectively than competitors who are competing across market segments (Porter 1985). For instance, a cost focus can target price sensitive customers that are otherwise excluded by mass market offerings (Hodgkinson 2013). This orientation has, for instance, driven European sport policy intervention in service delivery on the grounds of equity (Vandermeerschen and Scheerder 2017).

Faulkner and Bowman (1995) extend Porter's typology by incorporating the concept of perceived service benefits and perceived price in a typology that includes value added, price based and hybrid types. Here there is an opportunity for organizations to move between stances over time, though similarly to Porter's typology these types are considered to be distinct categories. Value added is reflective of Porter's differentiation strategy, such that higher perceived benefits are associated with the offering, but typically at a higher relative price. Implementing a price based stance requires low pricing while maintaining service quality, in contrast to Porter's cost leadership which does not 
necessarily result in low pricing. To be successful, this strategy requires customers to view price as an important determinant of purchasing behavior (Hodgkinson 2013) and as Vining $(2011,78)$ notes, "If agency prices are forced to approximate the marginal costs of delivery, then they may be subject to competition” which is central to the price-based strategic stance. While Porter (1985) contended that organizations should not pursue multiple generic strategies at any one time, owing to degradation of competitiveness, Faulkner and Bowman (1995) argue that it is possible to provide value at a lower price to differentiators, but at a level higher than price based types, which they refer to as hybrid. While the strategy literature has identified basic strategy categorizations, it does not necessarily mean that providers will strictly follow one type. Therefore, Hodgkinson and Hughes (2014) raise the question: can organizations pursue low cost, cost focus, value added, low price, and hybrid strategy types concurrently? The answer they uncover is yes, to lesser or greater degrees. Thus, there is a need to consider these basic strategy types as dimensions of strategy that can be mixed together to create different strategy configurations. Though “existing evidence provides preliminary clues about the strategies that are, on average, more likely to lead to better performance, and the circumstances under which they are most effective...the theoretical and empirical foundations of our knowledge on strategy in the public sector are very thin” (Boyne and Walker 2010, 189 [emphasis added]). We explore the strategy configurations among ownership types to determine how different public service providers can ensure a sustainable advantage compared with rival organizations (Hansen and Jacobsen 2016). In doing so, we offer a more nuanced explanation of strategy effects. 
Moreover, it is acknowledged that organizations' strategic stance and performance goals will be influenced by prioritized stakeholder groups (Bryson 2004). While public sector services are shaped by strategic considerations (Boyne and Walker 2010), performance criteria and their importance may vary depending on the stakeholders prioritized (Andersen et al. 2016). Hence, if service priorities vary among ownership types, this in turn may influence the performance goals different ownership types aspire to as well as the strategy configurations pursued. Yet, "the identity of prioritized stakeholders is seldom explicitly mentioned in comparisons of performance studies” (Andersen et al. 2016, 4), thus, we seek to capture this through additional analysis.

\section{The ideal profile approach}

Following the theorization of Venkatraman (1989), an ideal strategy profile is defined as the level of resource deployments along a set of strategy dimensions that are specific to a particular environment or service setting. A service organization's degree of adherence to such a multidimensional strategy profile will be positively related to performance if it has a high level of setting-strategy fit. Deviation from this profile implies a weakness in setting-strategy fit resulting in a negative effect on performance. These effects are conceptualized and assessed as profile deviation (Vorhies and Morgan 2003).

On the few occasions that configurational analysis has been adopted in public management investigation, studies have not examined the effect of strategy configurations among ownership types (e.g. Beynon et al. 2015; Hodgkinson and Hughes 2014). Using configuration theory we explore the strategy configurations pursued by the 
highest performers for each ownership type, "these configurations are ideal because they represent complex gestalts of multiple, interdependent, and mutually reinforcing organizational characteristics that enable businesses to achieve their strategic goals” (Vorhies and Morgan 2003, 101). In other words, the assumption is made that higher performing service providers will differ from poorer performing providers in their strategy configuration. Thus, the specific combination of strategy dimensions adopted by the highest performers is deemed the ideal strategy profile because they have configured their strategy in a way that enables superior performance (Hughes and Morgan 2008; Venkatraman 1989; Vorhies and Morgan 2003). While the strategy profile(s) of lower performing service providers is deemed the non-ideal. The ideal profile approach is particularly appropriate for this exploratory study, as it allows for the specification of an ideal profile to be empirically developed and in turn, provides the ability to demonstrate whether or not adherence to an ideal strategy profile has systematic implications for performance among ownership types (for a detailed overview of ideal profile analysis see Hughes and Morgan 2008; Venkatraman 1989, 1990; Vorhies and Morgan 2003).

\section{EXPLORATORY MODEL}

The aim of this exploratory model is twofold. First, we attempt to identify strategy configurations that contribute to significant differences in performance among ownership types and thus develop insights into how higher performing service providers differ from lower performing counterparts. This will point to how different ownership types generate performance and where performance returns are realized. Second, we 
account for differences in the prioritized stakeholders between ownership types to help our interpretation of the ideal strategy profiles and their respective performance outcomes. Three ownership types are examined:

First, public ownership involves local government authorities’ directly managing service delivery. The local authority takes full responsibility for income, expenditure, pricing and programming, and is accountable for all risk involved. Consequently, inhouse public providers receive a considerably higher level of local authority subsidy than any other ownership type. However, long term strategic financial planning is weak, since investments often depend on annual budget planning cycles, with leisure departments needing to bid against other council departments with higher political priority (Audit Commission 2006). With restricted access to capital, very little time and money is spent on addressing the needs of customers, illustrated by ineffective marketing and missed opportunities to increase income, address the needs of priority groups, and improve overall participation (Audit Commission 2006). The characteristics of this ownership type would then suggest a bias toward a strategic stance of low cost above all other strategy dimensions.

Second, nonprofit ownership involves the local authority transferring the service to a nonprofit trust that retains all income and incurs all expenditure. The local authority usually leases premises to a nonprofit trust on a long term lease, typically between 15 and 25 years, in return for a nominal rent (Audit Commission 2006). Outsourcing to nonprofit trusts has been a response from local government to financial pressure since charitable trusts obtain various tax exemptions (Reid 2003). However, the reinvestment of 
significant levels of savings in leisure provision is infrequent and where taxation savings are reinvested they have supported maintenance budgets rather than assisted the needed improvement of facilities (Audit Commission 2006). The subsequent reduction of local government subsidies can increase financial pressures and as a result some are forced to concentrate on profit-oriented activities in order to establish financial stability (Audit Commission 2006). Given their charitable status, this ownership type will likely pursue cost focus and low price for social inclusion purposes.

Third, private ownership occurs when a private agent is granted the lease of a leisure facility, usually lasting anywhere from 5 to 30 years, and retains all income and is generally responsible for most expenditure. The cost incurred by the local authority is substantially lower than the setup costs incurred when choosing other ownership types (Audit Commission 2006). The aim here is to utilize the management skills and business acumen of private agents. The financial performance of private providers appears on average to be stronger than for the other ownership types, attributable to a superior level of customer profiling (Audit Commission 2006). Private ownership types invest more capital into public sector leisure facilities with regular investment in new equipment, redecoration, and refurbishment (Mintel 2005). Stance in this ownership type will likely reflect value added for higher pricing.

Regarding performance, there is a need to (i) cover different dimensions of performance to account for the possibility of performance tradeoffs (Andrews et al. 2011a) and (ii) clearly outline the goals and context of the research setting to justify those dimensions examined (Andersen et al. 2016). The three performance dimensions of 
customer, business, and social reflect the multiple and often conflicting goals present in the sector (Boyne and Walker 2010). More than this, they reflect the reasoning of Vining (2011) that in the application of private sector management frameworks, goal differences between the private sector and public sector must be acknowledged and explicitly incorporated. Following Vining's (2011) overview of Moore’s conception of public value, two of the three performance dimensions examined here are consistent with the normative perspective of public agencies. Specifically, the customer dimension reflects public value as customer satisfaction and the social dimension reflects public value as the achievement of political mandates (such as the aim to increase sport participation among disadvantaged citizens in UK sport policy). The business dimension comprising traditional for-profit measures such as profitability and market share would typically be deemed inapplicable to the public sector context (Vining 2011). However, as Andersen and Jakobsen (2011), and Hansen and Ferlie (2016), and Vining (2011) illustrate, there are many competitive service settings where customers are charged to use a public service, where intense competitive rivalry can exist, and where economic performance is pivotal to service sustainability; leisure is a case in point.

The analysis does not begin with any a priori expectations about the strategy configurations of different ownership types, nor in how they differ, but we present three exploratory propositions: first, the strategy configurations of different ownership types will comprise distinctive combinations of basic strategy dimensions; second, the ideal strategy configuration will vary among different ownership types; and third, the 
performance implications of these ideal strategy configurations will vary by ownership type

\section{RESEARCH METHODS}

\section{Study context}

The unit of analysis is the leisure facilities overseen by English local governments. In England leisure services are discretionary in that local government authorities can choose whether or not they make these available to their community, which contributes to the variability in provision among local authorities. In urban areas, leisure service provision is the responsibility of London boroughs, metropolitan boroughs, and unitary authorities, and in rural areas, service provision is the responsibility of district councils (Alonso et al. 2015). Under the conditions of market supply and demand, leisure facilities are embroiled in market processes and must develop strategies that allow them to compete and succeed (Walker et al. 2011). In other words, a leisure facility experiencing market failure may be forced to close, given the reliance on income from the market as opposed to public funding.

We acknowledge that public leisure is not a homogeneous field and that both strategy and ownership may be contingent on the specific kind of services provided. In our research design, therefore, we control for the range of activities offered by each facility (for public, nonprofit, and private ownership types) that comprise the target population from which our sample is derived. Doing so ensures that ownership types are 
comparable: of the 540 public providers, all offer a health and fitness suite, 314 have a swimming pool (58\%), and 401 have access to a sports hall (74\%). There is a fitness suite facility in all 287 nonprofit providers, with 196 of those offering a swimming pool (68\%), and 204 a sports hall (71\%). Finally, out of the 233 private providers, all include a fitness suite in their provision, with 185 providing a pool (79\%) and 161 offering a sports hall (69\%).

\section{Data generation}

To circumvent common method bias issues, the data is drawn from three separate sources: (1) a mail survey questionnaire that we administered to leisure facilities in England to obtain data on strategic stance, customer performance, and business performance; (2) secondary objective data on ownership types gathered annually by Leisure DB in a survey of all facilities in the UK (to inform Government records of leisure provision in the UK); and, (3) secondary objective data on social performance collected by Leisure DB in a separate audit of facilities.

A four stage survey administration protocol was followed and involved prenotification, mailing of a full questionnaire pack, first reminder letter, and second reminder consisting of a full questionnaire pack. As recommended by Jakobsen and Jensen (2015) and Podsakoff, MacKenzie, Lee, and Podsakoff (2003), a number of precautions were taken to strengthen the survey instrument against potential common method bias, including: different response formats across questions; guarantees of respondent confidentiality and anonymity to reduce respondent apprehension; assurances to respondents that there were no right or wrong answers; measurement scales placed in 
random order; non idealized responses and wording neutrality adopted; questionnaire length reduced; and detailed instructions for its completion provided. Consistent with extant research examining the strategic characteristics of service providers and given the unit of analysis, we selected facility level managers as key informants. 280 of those surveyed responded resulting in an overall response rate of $26 \%$. The total number of respondents comprising each ownership type is: 152 public facilities, 75 nonprofit facilities, and 53 private facilities. Non response bias was examined by comparing a random sample of 100 respondents and 100 non respondents using objective data on adult membership numbers and cost of access. No significant differences were found for adult membership ( $\mathrm{F}=.129$; $\mathrm{ns})$ nor cost $(\mathrm{F}=2.126$; $\mathrm{ns})$.

\section{Measures}

\section{Service performance}

First, customer performance comprises customer satisfaction, customer value, quality of services, and development of services. Second, four business performance items are used that place emphasis on new customer sales, profitability, market share, and marketing. Performance measures were scaled as (1) very poor to (7) excellent, when comparing performance over the past 3 years to that of other competing facilities. Scale reliability was assessed through Cronbach Alpha. Both the business performance $(\alpha=$ $0.82)$ and customer performance $(\alpha=0.81)$ scales were deemed reliable. Third, social performance was gauged using objective individual facility usage records compared with the postcode analysis of the population in the facility's three mile catchment area. The focus here is on the participation of lower socioeconomic groups and older people. 
Including the three dimensions of performance creates a data set with both subjective and objective measures of performance, which is rare in public management research and reduces the risk of common method bias (Meier and O’Toole 2013). However, a limitation of this measure is that access to objective social inclusion data for the whole sample was not available. Of those facilities that responded, social inclusion data was only available for 19 publicly-managed facilities, 18 nonprofit facilities, and 17 privatelymanaged facilities.

\section{Strategy dimensions}

Strategy descriptors were drawn from Porter’s (1985), and Faulkner and Bowman's (1995) strategy typologies and included: low cost, cost focus, value added, low price, and hybrid. In adopting the self-typing paragraph descriptor approach (James and Hatten 1995) facility managers characterized the facility strategy being pursued from five short unlabelled paragraphs that depicted the strategy dimensions under examination (Appendix 1). Since public organizations vary in the extent to which they prioritize different strategies (Hodgkinson and Hughes 2014) and in following established practice (e.g. Boyne and Walker 2010), the strategy measures reflect the extent to which survey respondents agree that their organization can be characterized as low cost, cost focus, value added, low price, and hybrid on a Likert scale ranging from (1) "very little” to (7) "great deal”.

\section{Data analysis}


We would expect that the highest performers will pursue a different strategy configuration relative to their lower performing counterparts. This is the fundamental tenet of profile analysis (Venkatraman 1990). In other words, if the strategy pursued by the highest performers can be identified this can be classified as the ideal profile for others to follow, i.e. the gold standard. Conversely, calculating the profile deviation score reflects the extent to which the rest differ from the highest performers, and if this difference is statistically significant deviation from the ideal strategy configuration can be deemed negative for performance (Venkatraman 1989, 1990; Vorhies and Morgan 2003). This technique captures the complexity of strategy effects in the public sector and is akin to the benchmarking approaches English local governments have used to "recognize the best performing councils and spread best practice" (Ashworth et al. 2009, 174); hence the focus on the highest performers to determine the ideal strategy configurations.

Specifically, the ideal profile approach is used to empirically derive the strategy configuration of the highest performers for business performance, customer performance, and social performance, for each ownership type (public, non-profit, private). Consistent with extant literature, the highest performing public, non-profit, and private service providers are identified as those that fall within the top $15 \%$ boundary on performance scores (Hughes and Morgan 2008; Venkatraman 1990). The mean scores reported by these highest performers across the five strategy dimensions (i.e. the degree to which they emphasize low cost, cost focus, value added, low price, and hybrid strategy dimensions) are then calculated for each ownership type. To be clear, this is a subgroup of the total 
respondent samples (for each ownership type) that forms the ideal strategy profile ${ }^{1}$. Next, an ideal profile deviation score is calculated by subtracting the mean values reported by lower performers (i.e. the rest of the ownership sample) from the mean values reported by the highest performers, across the same basic strategy dimensions. These are then squared, summed, and square rooted to create a profile deviation score (Venkatraman 1990). To emphasise, a negative relationship between the strategy profile deviation score and performance would indicate that the ideal strategy empirically derived from the highest performers is conducive for higher performance. To assess the robustness of the results, regressions containing deviation from the ideal strategy profile of the highest performers are compared with models containing deviation from the alternative non ideal strategy profile of the lower performers (Hughes and Morgan 2008); if no differences are reported, strategy has no significant effect.

\section{RESULTS}

This section presents the composition of the ideal strategy profiles relative to the non ideal profiles for each ownership type. The regression results are presented in Table 1 and the ideal and non ideal strategy profile mean values are shown in Appendix 2 and 3. The findings presented in Table 1 support suggestions that strategy does matter to the ownership-performance relationship and puts into spotlight important performance tradeoffs that exist between customer performance, business performance, and social performance.

\footnotetext{
${ }^{1}$ We did not replace missing values for any respondent. There was one instance of missing data for customer performance and four cases on business performance for public ownership types only.
} 


\section{$<<<$ Insert Table 1 about here $>>>$}

For public ownership, the results demonstrate deteriorations in business performance $(-0.31, p \leq 0.01)$ and social performance $(-0.45 ; p \leq 0.10)$ when they deviate from the ideal strategy profile. For nonprofit and private ownership types, deteriorations in customer performance are observed when they deviate from the ideal strategy profile (nonprofit: $-0.39 ; p \leq 0.01$; private: $-0.27 ; p \leq 0.10$ ). Nonprofit types in addition suffer reduced social performance when deviating from the ideal strategy profile $(-0.72 ; p \leq$ 0.01). There appear, then, to be performance tradeoffs at play when the role of strategy is accounted for that must be balanced against ownership type for service delivery.

Nonsignificant findings imply that deviation from the ideal strategy combination does not materially affect performance. For instance, public providers do not suffer deteriorations in customer performance when they do not closely match the strategy profile of the highest performers. This suggests other factors are at play in explaining performance in this case. The same is true for nonprofit ownership for business performance and for private ownership for business and social performance. For completeness, we replicate this analysis with organizational size as a control variable using objective data obtained on total membership of each leisure facility as a proxy. The results are presented in Appendix 4 and as can be observed, organizational size is not a significant contributor to explaining performance in any of the regression models and the results of the ideal profiles remain unchanged.

We now explain the form of the ideal strategy configurations among ownership types based on the degrees of priority accorded to the five different basic strategic stances 
(e.g. Beynon et al. 2015): for public ownership the ideal strategy configuration for business performance prioritizes value added (6.00) and hybrid (5.25) dimensions, and for social performance cost focus (7.00), low price (7.00) and value added (6.00) dimensions. For nonprofit ownership the ideal strategy configuration for customer performance prioritizes cost focus (6.00), low price (5.64), and to a much lesser extent value added (4.73). Similarly, for social performance, the ideal configuration emphasizes cost focus (6.00), low price (5.00) and hybrid (5.00) dimensions. Finally, for private ownership customer performance advantages are achievable through a strategy configuration that emphasizes hybrid (5.58), cost focus (5.25), and value added (5.08) dimensions.

\section{Additional analysis}

Multivariate analysis of variance was performed to examine differences in the identity of prioritized stakeholder groups among ownership types to shed light on the performance goals they may aspire to and strategy configurations pursued, with Tukey's post hoc test for identifying statistically significant differences among ownership types. For the purpose of additional analysis seven possible stakeholder groups were identified from discussions with five service managers, scholars in the field of public management, and with reference to the literature (e.g. Freeman 1984). The groups identified include local government, employees, customers, suppliers, funders, local community, and government agencies. In acknowledging that the priority of stakeholders will likely vary among ownership types, respondents rated these groups by their level of influence on the 
strategy development process on a Likert scale ranging from (1) “very little” to (7) "great deal”. Table 2 presents the results.

\section{$<<<$ Insert Table 2 about here $>>>$}

While it may be assumed that a normative approach to service provision is superficially, at least, more suited to public and nonprofit ownership types that are expected to focus on the intrinsic worth of wider groups and on issues such as public health, sport development, youth engagement, and so on, but evidence for this case is limited. We find no significant disparity in the prioritization of local community, government agencies, or customers between public and nonprofit ownership types relative to private providers. Though, we note that nonprofit providers prioritize customers to a greater extent than publicly-owned ones. The influence of local government in public provision versus the pressure to secure funds for nonprofit and private providers is the one clear difference between ownership types that emerges from table 2 .

\section{DISCUSSION}

This paper set out to examine how and where different ownership types generate performance returns by exploring the effects of strategy configurations. Three observations can be made: first, there are performance considerations that need to be taken when determining the best ownership type for managing public services; second, depending on ownership type strategy configurations have clear performance implications in many cases; third, and most importantly, the ideal strategy profile of each ownership type is more important for maximizing service performance and reconciling 
performance dimensions rather than simply ownership type in itself. Consistent with Andrews et al.'s (2011a) theorization, then, we find that ownership effects on performance are contingent on strategy. The findings thus concur with Andersen and Jakobsen’s (2011) rejection of the simplistic relationship between the type of ownership and service performance. Though outsourcing public sector service delivery to external ownership (e.g. nonprofit and private providers) is often looked to as a means to more effective and efficient service provision, the performance effects of ownership types must be explored in the context of strategy.

In environments with less public funding and lower degrees of political control, Boyne and Walker (2010) suggest that prospecting-responding to new customer needs in the marketplace through innovation-maybe a logical choice for public organizations. This is supported by Hodgkinson and Hughes (2014) who suggest that the ability to deliver superior value in response to changing customer needs faster than competitors, termed "value differentiation", is a means to greater performance returns. They also report that an "equilibrial" configuration that offers an above average value proposition while simultaneously balancing costs and prices for affordability is a secondary route to performance gains. Though Hodgkinson and Hughes (2014) sought to investigate the net effects of strategy configurations across ownership types rather than among ownership types, there are a number of similarities with the findings reported here at the disaggregated level. The ideal strategy profiles for each ownership type share common traits with the value differentiation and equilibrial strategy configurations reported to be the two most effective when average effects are examined (Hodgkinson and Hughes 
2014). Likewise, the non ideal strategy profiles presented here appear in many cases to reflect Hodgkinson and Hughes's (2014) chaotic stance, the least effective of their strategy configurations.

However, since extant research has only established the average effects of strategy in the sector (Boyne and Walker 2010) there is a danger of concluding that strategy is always important for the performance of public service organizations. This is not always the case which raises the need for stronger theory testing of the relationship between strategy profiles and service performance dimensions. Specifically, the relationship between strategy and ownership type deserves more attention in the public administration and management literatures as it is clearly evident that by neglecting environmental peculiarities such as ownership, full understanding of the capacity for strategy to influence service performance cannot be realized. For example, when deviation from the ideal profile is found to be nonsignificant, it is likely that other substantive organizational variables are at play and it is necessary to look again and identify contingencies that facilitate performance among ownership types.

Moreover, equifinality among the ideal strategy configurations adds further complexity when explaining strategy effects among ownership types that coexist in service delivery. To elaborate, the same ideal strategy profile can carry different performance outcomes depending on the type of ownership examined. For instance, an ideal strategy configuration that prioritizes cost focus, value added and low price delivers social performance advantages for public ownership, but a very similar strategy configuration carries customer performance advantages for nonprofit ownership. This 
finding would suggest that the same ideal strategy configuration may confer different performance outcomes between ownership types, and highlights the complexity of equifinality as raised by Venkatraman (1989). We interpret this finding to mean that the operationalization of strategic stance from the intended strategy to that which is being realized in practice may vary between ownership types. Such that while the strategy pursued may be similar between two different ownership types (i.e. their strategic stance as examined here), how it is interpreted and executed appears to vary such that what is being realized in practice may be very different, despite the similar strategy configuration adopted. In turn, variation in the realized strategy leads to differing outcomes among ownership types.

By using ownership as a key contingency there is an opportunity to better explain how strategy and management variables can shape performance, which may be necessary to provide stronger theory testing in public management research. Thus, the combination of strategic stance and action may be more complex than previously captured and strategy research would benefit from greater configurational thinking to establish what is being realized in practice; i.e. a move away from a focus on strategic intent toward a greater consideration of emergent strategy execution such as the role of improvisation.

Andrews et al. (2011a) reflect that the degree of political control might influence the relative weight attached to different dimensions of performance. The implication for public ownership types that face greater demands from multiple principals relative to nonprofit and private ownership types is that it may be impossible to achieve conflicting objectives that require contradictory strategies. Yet strategies can be mixed and combined 
and need not be mutually exclusive or in conflict (Boyne and Walker 2004). Here we present an ideal strategy configuration for the achievement of conflicting goals.

\section{IMPLICATIONS FOR PRACTICE}

Since the impact of ownership type appears in part contingent on the configuration of strategy, as inferred by Andrews et al. (2011a) and Boyne and Walker (2010), policymakers should reject axiomatic perceptions of ownership types (Andersen and Jakobsen 2011). For example, public ownership should not necessarily be viewed as a cost burden, given that with the ideal strategy profile business performance returns can be realized. Following the additional analysis, we acknowledge that political constraints may inhibit the voluntary choices of strategy at the facility level for public ownership (Alonso et al. 2016). Policy makers should therefore be mindful to reduce constraints imposed as the potential for public providers to balance business and social performance is much stronger relative to external ownership types (nonprofit and private).

To maximize business and social performance, publicly-managed facilities should emphasize value added, hybrid, cost focus, and low price. Nonprofit service providers should place strategic emphasis on cost focus, low price, and value added for maximizing customer performance, with additional emphasis on the hybrid dimension for social performance gains. Privately-managed facilities will experience customer performance gains through an ideal profile that simultaneously emphasizes value added, hybrid, and cost focus dimensions. Ergo, we suggest that managers should consider their existing strategy profile relative to their ideal profile and seek to modify strategy if it is 
inappropriate for achieving the desired performance goals for that ownership type. This is particularly important for the business and social performance of publicly-owned service providers; the customer and social performance of nonprofit providers; and, the customer performance of privately-owned public service providers.

\section{LIMITATIONS AND CONCLUSION}

This study uncovers ideal strategy configurations among ownership types. These ideal strategy configurations differ between ownership types and confer both social and business performance returns for public ownership, customer and social performance advantages for nonprofit ownership, and customer performance gains only for private ownership. However, this study was not without its limitations. First, by examining public, nonprofit, and private ownership types separately this study does not account for network effects that may occur when two or more service providers operate collaboratively within a single constituency. Future research should consider the embeddedness of ownership types into networks at the local government level. Second, it is likely that different service settings will require different strategy configurations for performance gains, thus it is difficult to generalize the results to other ownership types in

different functional categories (Rainey 2011). Third, whilst the data gathered is shown to be reliable it is ultimately cross sectional in nature and does not allow for temporal observations to be made. Fourth, focusing only on strategic stance enables identification of the ideal strategy profiles among different ownership types, but this neglects other internal or external characteristics at play that could influence performance. Thus, 
following configuration theory future research can seek to determine the optimum management and organizational factors that would enable different ownership types to adopt a new ideal strategy and contribute to public value creation at the domain level. Public value at this level is created through the activities of public service providers, service managers, and is influenced by service policy (Hodgkinson, Hannibal, Keating, Chester Buxton, and Bateman 2017). This interplay between actors, management, organizational, and policy factors can best be addressed through configurational approaches.

To conclude, while the strategy concept in the public sector remains conceptually ambiguous, the focus here is on strategic stance; a very specific element of strategy. Understanding why particular strategy configurations are pursued by different service providers is beyond the scope of this paper. Such an examination would have to account for management, organization, and external variables. Rather, this study concerns the effects of strategy configurations among ownership types. This is done in order to provide a more accurate understanding of the role of strategy at the disaggregated level, rather than only examining its average performance effects across the sector, which has thus far led to surface level understanding of strategy (Boyne and Walker 2010).

It is important to highlight that the three ownership types examined all coexist in service delivery, and represent different public service providers rather than different public sector organizations. Since higher performers differ considerably from their lower performing counterparts in the strategy configurations pursued under the same ownership type (e.g. private ownership does not uniformly pursue one strategy configuration, nor do 
public and nonprofit ownership types) future performance comparison studies must account for variation within each form of ownership as differences will inevitably be found. This is imperative if more fine grained insights on strategy and performance are to be uncovered.

\section{REFERENCES}

Alonso, J. M., R. Andrews and I. R. Hodgkinson. 2015. “Institutional, Ideological and Political Influences on Local Government Contracting: Evidence from England.” Public Administration 94(1): 244-262.

Andersen, L. B., A. Boesen and L. H. Pedersen. 2016. "Performance in Public Organizations: Clarifying the Conceptual Space.” Public Administration Review 76(6): 852-862.

Andersen, L. B. and M. Jakobsen. 2011. "Does Ownership Matter For The Provision of Professionalized Services? Hip Operations at Publicly and Privately Owned Clinics in Denmark.” Public Administration 89(3): 956-974.

Andrews, R., G. A. Boyne and R. M. Walker. 2011a. "Dimensions of Publicness and Organizational Performance: A Review of the Evidence.” Journal of Public Administration Research and Theory 21(3): 301-319.

Andrews, R., G. A. Boyne, K. J. Meier, L. J. O'Toole and R. M. Walker. 2011b. "Vertical Strategic Alignment and Public Service Performance.” Public Administration 90(1): 77-98. 
Andrews, R., G. A. Boyne, J. Law and R. M. Walker. 2008. “Organizational Strategy, External Regulation And Public Service Performance.” Public Administration 86(1): 185-203.

Andrews, R., G. A. Boyne, J. Law and R. M. Walker. 2009. Strategy, Structure and Process in the Public Sector: A Test of the Miles and Snow Model. Public Administration 87(4): 732-749.

Andrews, R., G. A. Boyne and R. M. Walker. 2006. "Strategy Content and Organizational Performance: An Empirical Analysis.” Public Administration Review 66(1): 52-63.

Ashworth, R., G. Boyne, and R. Delbridge. 2009. “Escape From the Iron Cage? Organizational Change and Isomorphic Pressures in the Public Sector.” Journal of Public Administration Research and Theory 19(1): 165-187.

Audit Commission. 2006. Public Sports and Recreation Services: Making Them Fit for the Future. Audit Commission for Local Authorities and the National Health Service in England, Local Government National Report, June.

Beynon, M. J., R. Andrews and G. A. Boyne. 2015. “Evidence-based Modelling of Hybrid Organizational Strategies." Computational and Mathematical Organization Theory, 21(1): 1-23.

Boyne, G. A. 2002. “Public and Private Management: What’s the Difference?” Journal of Management Studies 39(1): 97-122. 
Boyne, G. A. and R. M. Walker. 2004. "Strategy Content and Public Service Organizations.” Journal of Public Administration Research and Theory 14(2): 231-252.

Boyne, G. A. and R. M. Walker. 2010. “Strategic Management and Public Service Performance: The Way Ahead.” Public Administration Review 70(SI): S185-S192.

Bryson, J. M. 2004. "What to do when Stakeholders Matter.” Public Management Review 6(1): 21-53.

DeSarbo, W. S., C. A. Di Benedetto, M. Song and I. Sinha. 2005. "Revisiting the Miles and Snow Strategic Framework: Uncovering Interrelationships between Strategic Types, Capabilities, Environmental Uncertainty, and Firm Performance.” Strategic Management Journal 26(1): 47-74.

Faulkner, D. and C. Bowman. 1995. The Essence of Competitive Strategy. London: Prentice Hall.

Freeman, R. E. 1984. Stakeholder Management. London: Pitman Books Limited. Hansen, J. and E. Ferlie. 2016. “Applying Strategic Management Theories in Public Sector Organizations: Developing a Typology.” Public Management Review 18(1): 1-19.

Hansen, J. R. and C. B. Jacobsen. 2016. "Changing Strategy Processes and Strategy Content in Public Sector Organizations? A Longitudinal Case Study of NPM Reforms’ Influence on Strategic Management.” British Journal of Management 27(2): 373-389 
Hodgkinson, I. R. 2013. “Are Generic Strategies "Fit For Purpose” in a Public Service Context?.” Public Policy and Administration 28(1): 90-111.

Hodgkinson, I. R., C. Hannibal, B. W. Keating, R. Chester Buxton, and N. Bateman. 2017. “Toward a Public Service Management: Past, Present, and Future Directions”. Journal of Service Management 28(5): 998-1023.

Hodgkinson, I. R. and P. Hughes. 2014. "Strategy Content and Public Service Provider Performance in the UK: An Alternative Approach.” Public Administration 92(3): 707-726.

Hughes, P. and R. E. Morgan. 2007. “A Resource-Advantage Perspective of ProductMarket Strategy Performance and Strategic Capital in High Technology Firms.” Industrial Marketing Management 36(4): 503-17.

Jakobsen, M. and R. Jensen. 2015. “Common Method Bias in Public Management Studies.” International Public Management Journal 18(1): 3-30.

James, W. L. and K. J. Hatten. 1995. "Further Evidence on the Validity of the SelfTyping Paragraph Approach: Miles and Snow Strategic Archetypes in Banking.” Strategic Management Journal 16(2): 161-168.

Johnson, G., K. Scholes, and R. Whittington. 2008. Exploring Corporate Strategy. Essex: Prentice Hall.

Meier, K. J., L. J. O'Toole, G. A. Boyne and R. M. Walker. 2007. “Strategic Management and the Performance of Public Organizations: Testing Venerable Ideas against Recent Theories.” Journal of Public Administration Research and Theory 17(3): 357-377. 
Meier, K. J., L. J. O’Toole, G. A. Boyne, R. M. Walker and R. Andrews. 2010.

"Alignment and Results: Testing the Interaction Effects of Strategy, Structure, and Environment from Miles and Snow.” Administration \& Society 42(2): 160192.

Miles, R. E. and C. C. Snow. 1978. Organizational Strategy, Structure, and Process. New York: McGraw-Hill.

Mintel. 2005. Leisure Review: Leisure Intelligence. London: Mintel International Group Limited.

Meier, K.J. and L.J. O’Toole. 2013. “Subjective Organizational Performance and Measurement Error: Common Source Bias and Spurious Relationships.” Journal of Public Administration Research and Theory 23(2): 429-456.

Mikkelsen, M.F. 2017. “Do Managers Face a Performance Trade-Off? Correlations between Production and Process Performance.” International Public Management Journal, Doi. 10967494.2016.1276495.

O'Toole, L. J. and K. J. Meier. 2004. "Parkinson’s Law and the New Public Management? Contracting Determinants and Service-Quality Consequences in Public Education.” Public Administration Review 64(3): 342-352.

O’Toole, L. J. and K. J. Meier. 2015. "Public Management, Context, and Performance: In Quest of a More General Theory.” Journal of Public Administration Research and Theory 25(1): 237-256. 
Podsakoff, P. M., S. B. MacKenzie, J-Y. Lee, and N. P. Podsakoff. 2003. “Common Method Biases in Behavioural Research: A Critical Review of the Literature and Recommended Remedies.” Journal of Applied Psychology 88(5): 879-903.

Porter, M. E. 1985. Competitive Advantage: Creating and Sustaining Superior Performance. New York: Macmillan Publishing.

Rainey, H. G. 2011. “Sampling Designs for Analyzing Publicness: Alternatives and Their Strengths and Weaknesses.” Journal of Public Administration Research and Theory 21(3): 321-345.

Reid, G. 2003. “Charitable Trusts: Municipal Leisure’s ‘Third Way’?” Managing Leisure 8(4): 171-183.

Rho, E. 2013. “Contracting Revisited: Determinants and Consequences of Contracting Out for Public Education Services.” Public Administration Review 73(2): 327-337.

Simmons, R. 2004. "A Trend to Trust? The Rise of New Leisure Trusts in the UK.” Managing Leisure 9(3): 159-177.

Vandermeerschen, H. and J. Scheerder. 2017. “Sport Managers’ Perspectives on Poverty and Sport: The Role of Local Sport Authorities”. Sport Management Review, DOI: http://dx.doi.org/10.1016/j.smr.2017.02.002.

Venkatraman, N. 1990. "Performance Implications of Strategic Coalignment: A Methodological Perspective.” Journal of Management Studies 27(1): 19-41. Venkatraman, N. 1989. “The concept of Fit in Strategy Research: Toward Verbal and Statistical Correspondence. Academy of Management Review 14(3): 423-444. 
Vining, A. R. 2011. “Public Agency External Analysis Using a Modified 'Five Forces' Framework”. International Public Management Journal 14(1): 63-105.

Vorhies, D. W. and N. A. Morgan. 2003. “A Configuration Theory Assessment of Marketing Organization Fit with Business Strategy and its Relationship with Marketing Performance. Journal of Marketing 67(1): 100-115.

Walker, R. M., R. Andrews, G. A. Boyne, K. J. Meier and L. J. O’Toole. 2010. “Wakeup Call: Strategic Management, Network Alarms and Performance.” Public Administration Review 70(5): 731-41.

Walker, R. M., G. A. Brewer, G. A. Boyne and C. N. Avellaneda. 2011. "Market Orientation And Public Service Performance: New Public Management Gone Mad?.” Public Administration Review 71(5): 707-717. 
Table 1 Regression results ${ }^{\mathrm{a}}$

\begin{tabular}{|c|c|c|c|c|c|c|}
\hline & \multicolumn{3}{|c|}{ 'Ideal' Fit Models } & \multicolumn{3}{|c|}{ Random 'Non-Ideal' Models } \\
\hline & $\begin{array}{l}\text { Profile } \\
\text { deviation } \\
\text { (misfit) }\end{array}$ & $R^{2}$ & $F$-value & $\begin{array}{l}\text { Profile } \\
\text { deviation } \\
\text { (misfit) }\end{array}$ & $R^{2}$ & $F$-value \\
\hline \multicolumn{7}{|l|}{ Customer } \\
\hline \multicolumn{7}{|c|}{ Performance } \\
\hline Public & -0.13 & 0.02 & 2.06 & $0.32 * *$ & 0.10 & $13.11^{* *}$ \\
\hline Nonprofit & $-0.39 * *$ & 0.15 & $9.02 * *$ & -0.12 & 0.01 & 0.70 \\
\hline Private & $-0.27 \dagger$ & 0.08 & $3.09 \dagger$ & 0.01 & 0.01 & 0.01 \\
\hline \multicolumn{7}{|l|}{ Business } \\
\hline \multicolumn{7}{|c|}{ Performance } \\
\hline Public & $-0.31 * *$ & 0.09 & 14.30 & $0.15 \dagger$ & 0.02 & $2.97 \dagger$ \\
\hline Nonprofit & -0.03 & 0.01 & 0.05 & -0.03 & 0.01 & 0.07 \\
\hline Private & -0.15 & 0.02 & 0.81 & -0.09 & 0.01 & 0.32 \\
\hline \multicolumn{7}{|l|}{ Social } \\
\hline \multicolumn{7}{|c|}{ Performance } \\
\hline Public & $-0.45 \dagger$ & 0.20 & $3.75 \dagger$ & $0.61^{* *}$ & 0.37 & $8.81 * *$ \\
\hline Nonprofit & $-0.72 * *$ & 0.52 & $13.82 * *$ & -0.33 & 0.11 & 1.61 \\
\hline Private & -0.27 & 0.07 & 0.94 & -0.40 & 0.16 & 2.24 \\
\hline
\end{tabular}

Notes: ${ }^{\text {a }}$ Customer Performance, Business Performance and Social Performance represent the Dependent

Variables; Profile Deviation is the Independent Variable. ${ }^{* *} p \leq 0.01 .{ }^{*} p \leq 0.05 . \dagger p \leq 0.10$ 
Table 2 MANOVA results for ownership and groups of influence

\begin{tabular}{|c|c|c|c|c|c|}
\hline \multirow{2}{*}{$\begin{array}{l}\text { Stakeholder } \\
\text { Influence }\end{array}$} & \multicolumn{3}{|c|}{ Ownership (Means [SD]) } & \multirow[t]{2}{*}{ F-ratio } & \multirow[t]{2}{*}{ Tukey Test $(p \leq .05)$} \\
\hline & Public & Nonprofit & Private & & \\
\hline Local Authority & $5.97(1.22)$ & $4.32(1.84)$ & $\begin{array}{c}4.68 \\
(1.39)\end{array}$ & $38.41 * *$ & $\begin{array}{c}\text { Nonprofit }<\text { Public } \\
\text { Private }<\text { Public }\end{array}$ \\
\hline Employees & $4.11(1.54)$ & $4.51(1.71)$ & $\begin{array}{c}3.98 \\
(1.61)\end{array}$ & 2.14 & NSD \\
\hline Customers & $4.38(1.47)$ & $4.89(1.65)$ & $\begin{array}{c}4.69 \\
(1.67)\end{array}$ & $2.88 *$ & Public $<$ Nonprofit \\
\hline Suppliers & $2.05(1.38)$ & $2.36(1.38)$ & $\begin{array}{c}2.21 \\
(1.36)\end{array}$ & 1.37 & NSD \\
\hline Lenders & $1.36(0.92)$ & $1.95(1.46)$ & $\begin{array}{c}2.35 \\
(1.96)\end{array}$ & $12.57 * *$ & $\begin{array}{c}\text { Public }<\text { Nonprofit } \\
\text { Public }<\text { Private }\end{array}$ \\
\hline Local Community & $3.83(1.50)$ & $4.11(1.68)$ & $\begin{array}{c}3.83 \\
(1.49)\end{array}$ & 0.89 & NSD \\
\hline $\begin{array}{l}\text { Government } \\
\text { Agencies }\end{array}$ & $2.65(1.66)$ & $2.39(1.26)$ & $\begin{array}{c}2.54 \\
(1.49)\end{array}$ & 0.72 & NSD \\
\hline
\end{tabular}

Notes: ${ }^{* *} p \leq 0.01 .{ }^{*} p \leq 0.05$. NSD: no significant differences found. 


\section{Appendix 1 Descriptor strategy statements}

Low Cost, striving for a low cost position relative to competitors, achieved through an experience curve, tight cost and overhead control, and cost minimization in areas like service and advertising.

Cost focus, reducing inequalities between the least advantaged groups and communities and the rest of society. The leisure facility seeks to include all citizens, achieved through targeted programming.

Value Added, differentiating the product or service offering of the leisure facility, providing a service that is superior to competitors. Costs are of secondary significance to providing the service offering.

Low Price, providing a service for those who cannot afford the opportunities offered by the private sector. A central motivation of the service is to ensure access for all citizens achieved through price subsidies or providing a low entry price.

Hybrid, differentiating the product or service offering of the leisure facility to provide a service that is superior to competitors, whilst simultaneously maintaining a tight control on costs for a lower cost-base relative to competitors. 
Appendix 2 Ideal strategy profiles ${ }^{\mathrm{a}}$

\begin{tabular}{lcccccc}
\hline & \multicolumn{2}{c}{ Customer Performance } & \multicolumn{2}{c}{ Business Performance } & \multicolumn{2}{c}{ Social Performance } \\
\cline { 2 - 6 } & Mean & S.D. & Mean & S.D. & Mean & S.D. \\
\hline Public & & & & & & \\
Low Cost & 4.19 & 1.90 & 3.00 & 2.45 & 4.50 & 3.53 \\
Cost Focus & 5.65 & 1.36 & 4.63 & 1.19 & $\mathbf{7 . 0 0}$ & $\mathbf{0 . 0 0}$ \\
Value & 4.89 & 1.71 & $\mathbf{6 . 0 0}$ & $\mathbf{2 . 1 4}$ & $\mathbf{6 . 0 0}$ & $\mathbf{1 . 4 1}$ \\
Added & & & & & & \\
Low Price & 4.81 & 1.97 & 4.13 & 2.36 & $\mathbf{7 . 0 0}$ & $\mathbf{0 . 0 0}$ \\
Hybrid & 4.62 & 1.72 & $\mathbf{5 . 2 5}$ & $\mathbf{1 . 9 1}$ & 5.50 & 0.71 \\
& & & & & & \\
Nonprofit & & & & & & \\
Low Cost & 3.64 & 1.65 & 3.50 & 1.84 & 2.00 & 1.00 \\
Cost Focus & $\mathbf{6 . 0 0}$ & $\mathbf{1 . 4 5}$ & 4.80 & 1.87 & $\mathbf{6 . 0 0}$ & $\mathbf{1 . 0 0}$ \\
Value & $\mathbf{4 . 7 3}$ & $\mathbf{1 . 7 8}$ & 5.10 & 1.20 & 4.67 & 1.53 \\
Added & & & & & & \\
Low Price & $\mathbf{5 . 6 4}$ & $\mathbf{1 . 2 9}$ & 5.60 & 0.97 & $\mathbf{5 . 0 0}$ & $\mathbf{1 . 0 0}$ \\
Hybrid & 4.64 & 1.94 & 5.90 & 0.74 & $\mathbf{5 . 0 0}$ & $\mathbf{2 . 6 5}$ \\
Private & & & & & & \\
Low Cost & 3.67 & 1.50 & 4.00 & 1.60 & 4.33 & 0.58 \\
Cost Focus & $\mathbf{5 . 2 5}$ & $\mathbf{1 . 5 4}$ & 5.17 & 1.64 & 4.00 & 2.65 \\
Value & $\mathbf{5 . 0 8}$ & $\mathbf{1 . 6 8}$ & 4.67 & 1.56 & 3.67 & 0.58 \\
Added & & & & & & \\
Low Price & 4.33 & 1.97 & 4.25 & 1.86 & 4.00 & 1.00 \\
Hybrid & $\mathbf{5 . 5 8}$ & $\mathbf{1 . 5 1}$ & 4.67 & 1.37 & 6.33 & 0.58 \\
\hline Nota Fig & & & & & & \\
\hline
\end{tabular}

Notes: ${ }^{\text {a }}$ Figures in bold emphasize strategic priorities. Figures are only bolded for the ideal profiles that significantly contribute to performance, as reflected in the results presented in Table 1. 
Appendix 3 Non ideal strategy profiles

\begin{tabular}{lcccccc}
\hline & \multicolumn{2}{c}{ Customer Performance } & \multicolumn{2}{c}{ Business Performance } & \multicolumn{2}{c}{ Social Performance } \\
\cline { 2 - 7 } & Mean & S.D. & Mean & S.D. & Mean & S.D. \\
\hline Public & & & & & & \\
Low Cost & 4.65 & 1.67 & 4.38 & 1.99 & 4.00 & 4.24 \\
Cost Focus & 5.54 & 1.68 & 5.63 & 1.41 & 6.00 & 1.41 \\
Value Added & 3.43 & 1.52 & 4.50 & 1.69 & 3.00 & 1.41 \\
Low Price & 5.11 & 1.52 & 5.25 & 2.12 & 4.50 & 2.12 \\
Hybrid & 3.38 & 1.57 & 3.19 & 1.41 & 2.00 & 1.41 \\
& & & & & & \\
Nonprofit & & & & & & \\
Low Cost & 4.32 & 2.03 & 4.20 & 2.15 & 3.67 & 2.08 \\
Cost Focus & 5.55 & 1.60 & 5.10 & 2.02 & 6.67 & 0.58 \\
Value Added & 4.59 & 1.53 & 4.00 & 1.49 & 4.00 & 2.65 \\
Low Price & 5.09 & 1.57 & 5.30 & 1.57 & 5.33 & 2.08 \\
Hybrid & 4.64 & 1.79 & 3.80 & 2.10 & 4.33 & 2.08 \\
& & & & & & \\
Private & & & & & & \\
Low Cost & 5.08 & 1.12 & 4.46 & 1.81 & 5.00 & 1.00 \\
Cost Focus & 5.85 & 1.28 & 5.23 & 1.36 & 5.00 & 2.65 \\
Value Added & 4.23 & 1.79 & 4.46 & 1.76 & 3.67 & 0.58 \\
Low Price & 5.08 & 1.75 & 5.08 & 1.75 & 4.67 & 0.58 \\
Hybrid & 4.38 & 1.89 & 4.69 & 1.18 & 6.00 & 1.00 \\
\hline
\end{tabular}


Appendix 4 Regression results with size as a control variable ${ }^{\mathrm{a}}$

\begin{tabular}{llc}
\hline & \multicolumn{1}{c}{ 'Ideal' Fit Models } \\
\hline Customer Performance & Profile deviation (misfit) & Size \\
Public & -0.15 & -0.12 \\
Nonprofit & $-0.38^{* *}$ & -0.07 \\
Private & $-0.27 \dagger$ & -0.01 \\
& & \\
Business Performance & & \\
Public & $-0.30^{* *}$ & 0.13 \\
Nonprofit & -0.02 & -0.11 \\
Private & -0.14 & 0.14 \\
& & \\
Social Performance & & -0.27 \\
Public & $-0.54^{*}$ & -0.04 \\
Nonprofit & $-0.73^{* *}$ & -0.11 \\
Private & -0.30 & \\
\hline
\end{tabular}

Notes: ${ }^{\text {a }}$ Customer Performance, Business Performance and Social Performance represent the Dependent

Variables; Profile Deviation is the Independent Variable. ${ }^{* *} p \leq 0.01 .{ }^{*} p \leq 0.05 . \dagger p \leq 0.10$ 